\title{
Erratum to: Screening newborns for metabolic disorders based on targeted metabolomics using tandem mass spectrometry
}

Hye-Ran Yoon, PhD

Biomedical \& Pharmaceutical Analysis Lab, College of Pharmacy, Duksung

Women's University, Seoul, Korea

\section{Erratum to: Ann Pediatr Endocrinol Metab. (2015) 20:119-124}

Unfortunately the original published article contains an inaccurate statement in Acknowledgements section. Please find the accurate Acknowledgement section below.

\section{Acknowledgments}

There is no Research Grant supported for this study

The online version of the original article can be found under doi: http://dx.doi.org/10.6065/ apem.2015.20.3.119. 